Philadelphia College of Osteopathic Medicine DigitalCommons@PCOM

PCOM Scholarly Papers

9-22-2014

\title{
Tbx5 is Required for Avian and Mammalian Epicardial Formation and Coronary Vasculogenesis.
}

Nata Y Diman

Gabriel Brooks

Boudewijn P Kruithof

Olivier Elemento

Jonathan G Seidman

See next page for additional authors

Follow this and additional works at: http://digitalcommons.pcom.edu/scholarly_papers

Part of the Developmental Biology Commons, and the Genetics Commons

\section{Recommended Citation}

Diman, Nata Y; Brooks, Gabriel; Kruithof, Boudewijn P; Elemento, Olivier; Seidman, Jonathan G; Seidman, Christine; Basson, Craig T; and Hatcher, Cathy J., "Tbx5 is Required for Avian and Mammalian Epicardial Formation and Coronary Vasculogenesis." (2014). PCOM Scholarly Papers. Paper 243.

http://digitalcommons.pcom.edu/scholarly_papers/243

This Article is brought to you for free and open access by DigitalCommons@PCOM. It has been accepted for inclusion in PCOM Scholarly Papers by an authorized administrator of DigitalCommons@PCOM. For more information, please contact library@pcom.edu. 
Authors

Nata Y Diman, Gabriel Brooks, Boudewijn P Kruithof, Olivier Elemento, Jonathan G Seidman, Christine Seidman, Craig T Basson, and Cathy J. Hatcher 


\title{
Circulation Research
}

\section{Tbx5 Is Required for Avian and Mammalian Epicardial Formation and Coronary Vasculogenesis}

Nata Y.S.-G. Diman, Gabriel Brooks, Boudewijn P.T. Kruithof, Olivier Elemento, J.G. Seidman, Christine E. Seidman, Craig T. Basson and Cathy J. Hatcher

Circ Res. 2014;115:834-844; originally published online September 22, 2014; doi: 10.1161/CIRCRESAHA.115.304379

Circulation Research is published by the American Heart Association, 7272 Greenville Avenue, Dallas, TX 75231 Copyright (C) 2014 American Heart Association, Inc. All rights reserved. Print ISSN: 0009-7330. Online ISSN: 1524-4571

The online version of this article, along with updated information and services, is located on the World Wide Web at:

http://circres.ahajournals.org/content/115/10/834

Data Supplement (unedited) at:

http://circres.ahajournals.org/content/suppl/2014/09/22/CIRCRESAHA.115.304379.DC1.html

\begin{abstract}
Permissions: Requests for permissions to reproduce figures, tables, or portions of articles originally published in Circulation Research can be obtained via RightsLink, a service of the Copyright Clearance Center, not the Editorial Office. Once the online version of the published article for which permission is being requested is located, click Request Permissions in the middle column of the Web page under Services. Further information about this process is available in the Permissions and Rights Question and Answer document.
\end{abstract}

Reprints: Information about reprints can be found online at: http://www.lww.com/reprints

Subscriptions: Information about subscribing to Circulation Research is online at: http://circres.ahajournals.org//subscriptions/ 


\title{
Tbx5 Is Required for Avian and Mammalian Epicardial Formation and Coronary Vasculogenesis
}

\author{
Nata Y.S.-G. Diman, Gabriel Brooks, Boudewijn P.T. Kruithof, Olivier Elemento, \\ J.G. Seidman, Christine E. Seidman, Craig T. Basson, Cathy J. Hatcher
}

Rationale: Holt-Oram syndrome is an autosomal dominant heart-hand syndrome caused by mutations in the TBX5 gene. Overexpression of Tbx5 in the chick proepicardial organ impaired coronary blood vessel formation. However, the potential activity of Tbx5 in the epicardium itself, and the role of Tbx5 in mammalian coronary vasculogenesis, remains largely unknown.

Objective: To evaluate the consequences of altered Tbx 5 gene dosage during proepicardial organ and epicardial development in the embryonic chick and mouse.

Methods and Results: Retroviral-mediated knockdown or upregulation of Tbx5 expression in the embryonic chick proepicardial organ and proepicardial-specific deletion of $T b x 5$ in the embryonic mouse (Tbx $\left.5^{\text {epi- }}\right)$ impaired normal proepicardial organ cell development, inhibited epicardial and coronary blood vessel formation, and altered developmental gene expression. The generation of epicardial-derived cells and their migration into the myocardium were impaired between embryonic day (E) 13.5 to 15.5 in mutant hearts because of delayed epicardial attachment to the myocardium and subepicardial accumulation of epicardial-derived cells. This caused defective coronary vasculogenesis associated with impaired vascular smooth muscle cell recruitment and reduced invasion of cardiac fibroblasts and endothelial cells into myocardium. In contrast to wild-type hearts that exhibited an elaborate ventricular vascular network, $T b x 5^{\text {epi-/ }}$ hearts displayed a marked decrease in vascular density that was associated with myocardial hypoxia as exemplified by hypoxia inducible factor- $1 \alpha$ upregulation and increased binding of hypoxyprobe-1. Tbx $5^{\text {epi-/ }}$ mice with such myocardial hypoxia exhibited reduced exercise capacity when compared with wild-type mice.

Conclusions: Our findings support a conserved Tbx5 dose-dependent requirement for both proepicardial and epicardial progenitor cell development in chick and in mouse coronary vascular formation. (Circ Res. 2014;115:834-844.)

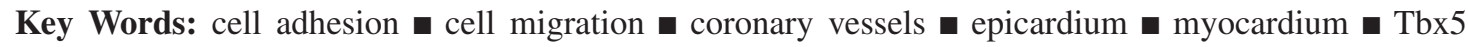
- transcription factors

$\mathrm{E}_{\mathrm{m}}^{\mathrm{p}}$ picardial formation and coronary vasculogenesis are highly regulated processes that involve a series of spatiotemporally regulated molecular and cellular events. ${ }^{1,2}$ These processes begin with formation of the proepicardial organ (PEO)/proepicardium and involve epicardial-derived cell (EPDC) transition. The PEO is located at the venous pole of the heart and is part of the septum transversum. This transitory structure is comprised of mesothelial cells morphologically visible in the mouse between embryonic day (E) 9 and 9.5. ${ }^{1} \mathrm{At}$ E10.5, the epicardium is formed and fully matured by E11.5. A subset of epicardial cells undergoes epithelial-mesenchymal transition (EMT) to generate EPDCs that delaminate and populate the subepicardial space and further migrate into the underlying myocardium. ${ }^{1,3}$ Here, they differentiate into the cellular elements of coronary blood vessels (ie, endothelial cells, smooth muscle cells [SMC], and cardiac fibroblasts). Subepicardial endothelial cells contribute to both coronary arteries and veins. ${ }^{4}$ The sinus venosus and endocardium also contribute coronary endothelial cells to form the developing coronary arteries. ${ }^{5,6}$ Subsequently, these cellular components coalesce and form the primitive vascular plexus that ultimately remodels to form the coronary blood vessels. Using various

Original received May 14, 2014; revision received September 17, 2014; accepted September 19, 2014. In August, 2014, the average time from submission to first decision for all original research papers submitted to Circulation Research was 13.55 days.

From the Center for Molecular Cardiology, Greenberg Division of Cardiology (N.Y.S.-G.D., G.B., B.P.T.K., C.T.B., C.J.H.) and Department of Physiology and Biophysics (O.E.), Weill Cornell Medical College, New York, NY; Department of Genetics, Harvard Medical School, Boston, MA (J.G.S., C.E.S.); and Department of Bio-Medical Sciences, Philadelphia College of Osteopathic Medicine, PA (C.J.H.).

This article was sent to Elizabeth M. McNally, Consulting Editor, for review by expert referees, editorial decision, and final disposition.

The online-only Data Supplement is available with this article at http://circres.ahajournals.org/lookup/suppl/doi:10.1161/CIRCRESAHA. 115.304379/-/DC1.

Correspondence to Cathy J. Hatcher, PhD, Department of Bio-Medical Sciences, Philadelphia College of Osteopathic Medicine, 4170 City Ave, Philadelphia, PA 19131. E-mail cathyha@pcom.edu; or Craig T. Basson, MD, PhD, Novartis Institutes for Bio-Medical Research, 220 Massachusetts Ave, Cambridge, MA 02139. E-mail craig.basson@novartis.com

(C) 2014 American Heart Association, Inc. 


\begin{tabular}{|c|c|}
\hline \multicolumn{2}{|c|}{ Nonstandard Abbreviations and Acronyms } \\
\hline cTbx5 & chick Tbx5 \\
\hline cTbx5As-CXL & CXL retrovirus encoding antisense chick Tbx5 \\
\hline CXIZ & control retrovirus encoding $\beta$-galactosidase \\
\hline E & embryonic day \\
\hline ECM & extracellular matrix \\
\hline EMT & epithelial-mesenchymal transformation \\
\hline EPDCs & epicardial-derived cells \\
\hline НH & Hamburger-Hamilton \\
\hline HOS & Holt-Oram syndrome \\
\hline mTbx5 & mouse Tbx5 \\
\hline PEO & proepicardial organ \\
\hline SMC & smooth muscle cell \\
\hline SM22 $\alpha$ & smooth muscle $22 \alpha$ (transgelin) \\
\hline Tbx & T-box \\
\hline Tbx5epir ${ }^{\prime-}$ & Tbx5 $5^{10 x / 10 x ; W t 1-C r e ~}$ \\
\hline Wt1 & Wilm's tumor 1 \\
\hline
\end{tabular}

mouse models with Cre-recombinase expressed in epicardial and/or EPDCs, investigators have demonstrated multiple contributions of EPDCs to coronary smooth muscle, coronary endothelium, the interstitial fibroblast population, and the atrioventricular junctional myocardium. ${ }^{1,2,7-10}$

The epicardium plays a pivotal role in cardiac development because paracrine-mediated secretion of epicardial factors, such as Wnts, erythropoietin, fibroblast growth factors, and retinoids, are important for embryonic compact myocardial growth ${ }^{1,2}$ and can be reactivated during cardiac injury and repair. ${ }^{11}$ PEO ablation/blockade that perturbs or delays epicardial formation and genetic ablation of various genes expressed in the proepicardium or myocardium leads to abnormal coronary vasculogenesis, myocardial defects, and potential embryonic lethality. ${ }^{1,2}$

T-box transcription factor genes, including $T b x 5$ and Tbx18, are expressed in the PEO or septum transversum. ${ }^{1,12-15}$ We previously showed that the manipulation of Tbx5 gene dosage in the chick PEO affects proepicardial cell migration and can impair avian coronary vasculogenesis. ${ }^{16}$ However, these studies did not address the potential activity of Tbx5 in the epicardium itself. The mechanisms by which $T b \times 5$ controls mammalian coronary vasculogenesis remain largely unknown, and the relevance of avian signaling to mammalian ontogeny was not tested. Holt-Oram syndrome (HOS) is a human inherited disorder caused by mutations in TBX5 and manifests as congenital cardiac septation and conduction defects in the setting of limb deformities. ${ }^{17,18}$ Some patients with HOS also exhibit left pericardium agenesis and anomalous coronary arteries along with ventricular septal defects ${ }^{19,20}$ consistent with a role for $T B X 5$ in epicardial/pericardial and myocardial development. Early embryonic lethality resulting from germline inactivation of $T b x 5$ in the mouse has precluded further investigation of the function of $T b \times 5$ in later stages of cardiac development, including epicardial formation and coronary vasculogenesis. $^{21}$

We have now developed strategies to investigate epicardial activity of $T b \times 5$ in the chick, and we have generated conditional mutant mice with Tbx5 deletion from the proepicardial and epicardial derivatives. We show that $T b \times 5$ expression in the proepicardium/PEO and epicardium is required for normal development of proepicardium/PEO cells, as well as proper epicardial formation and maturation. Tbx5 deficiency delays epicardial cell attachment to the myocardium, impairs production of EPDCs and their migration into the myocardium, and results in abnormal coronary vasculogenesis and murine ischemic cardiomyopathy. Our findings demonstrate that $T b \times 5$ is required both for proepicardial and for epicardial development in avian and in mammalian hearts and for establishment of the coronary vasculature.

\section{Methods}

Tbx $5^{\text {lox/lox } 21}$ and Wilm's tumor 1 (Wt1)-Cre ${ }^{8,22}$ mice have been described. Generation of retrovirus and in ovo retroviral injection was performed as previously described ${ }^{16}$ with the exception of epicardial infection that was accomplished by retroviral injection into the pericardial space of the embryonic chick.

An expanded Methods section, including all experimental procedures, is available in the Online Data Supplement.

\section{Results}

\section{Tbx5 Expression in Chick and Mouse PEO and Derivatives}

Although Tbx5 myocardial and endocardial expressions have been previously described during cardiogenesis, ${ }^{16,23,24}$ the detailed spatiotemporal patterns of chick and mouse Tbx5 expression in the PEO/proepicardium and epicardium have not been well defined. In situ hybridization in chick embryos revealed heterogeneous staining in the PEO at HamburgerHamilton (HH) stage 16 or E3 (Online Figure IA and IE). By HH22 (E4), chick Tbx5 (cTbx5) remained detectable in the PEO remnant and in migrating proepicardial cells contacting the myocardium. By HH26 (E5), cTbx5 was evident in the newly formed epicardium (Online Figure IB and IF). A similar expression pattern for mouse Tbx 5 (mTbx5) was observed by in situ hybridization at the corresponding developmental stages of E9.5 (Online Figure IC and IG) and E10.5 in the mouse (Online Figure ID and IH). Immunostaining for mTbx 5 protein expression showed a spatiotemporal pattern similar to that observed with our in situ hybridization data. At E9.5, nuclear expression of mTbx 5 protein was evident in the murine proepicardium in a heterogeneous pattern (Online Figure II and IL). At E10.5, mTbx5 protein expression was evident in the nascent epicardium and pericardium (Online Figure IJ). Whereas some epicardial cells were Tbx5-negative (online Figure IM), all epicardial cells expressed Wt1 (Online Figure IN). Tbx 5 expression was decreased in the epicardial cells by E11.5 (Online Figure IK and IO), but persists into adulthood as previously shown. ${ }^{25}$ Thus, these analyses support spatial and temporal restriction of $T b \times 5$ expression in the embryonic chick and murine PEO/proepicardium and epicardium.

\section{Tbx5 Contributes to In Vitro and In Vivo Proepicardial Cell Development}

We previously demonstrated that Tbx5 overexpression disrupts chick proepicardial cell migration in vitro. ${ }^{16}$ To determine the requirement for cTbx5 in epicardial formation and coronary vasculogenesis, we used retroviral-mediated 
transgenesis with an antisense (cTbx5As-CXL) construct (Online Figure IIA) to knock down cTbx5 expression in cultured PEO explants in a manner similar to our previous TBX5 overexpression studies. ${ }^{16}$ Retroviral-mediated cTbx5 knockdown produced a $45 \%$ reduction of in vitro migration of proepicardial cells to the periphery of PEO explants compared with control CXL PEOs (Online Figure IIIA-IIIC). This demonstrated that cTbx 5 expression is required for in vitro chick proepicardial cell migration.

To confirm that this requirement for cTbx 5 was preserved in PEO cell migration and coronary vasculogenesis in vivo, we injected either control $\mathrm{CXL}^{26}$ or $c 7 b \times 5 A s-\mathrm{CXL}$ retrovirus into chick PEOs in ovo at HH17-18 (E3; Online Figure IIA). By 8 hours after injection, we observed transgene expression in the PEO as shown by X-gal staining for $\beta$-galactosidase activity for both retroviruses (Figure 1A and 1E). Twentyfour hours after PEO injection with the control CXL virus, $\beta$-galactosidase-positive cells were visible on the surface of the heart (Figure 1B). However, embryos that received PEO injections of cTbx5As-CXL to knock down Tbx5 expression exhibited only scant $\beta$-galactosidase-positive cells on the surface of the heart (Figure 1F). By 12 days after injection, E15 CXL-infected embryos (15/15 embryos) displayed prominent $\beta$-galactosidase-positive staining in the coronary vasculature (Figure 1C and 1D). Hearts from E15 embryos infected with cTbx5As-CXL did not show any evidence of $\beta$-galactosidase staining in the coronary vessels (0/13 embryos; Figure $1 G)$. All hearts exhibited minimal levels of myocardial staining at 24 hours to 12 days after injection because of slight retroviral leakage into the myocardium during the initial pressure injection of the retrovirus as evidenced by $\beta$-galactosidase staining of myocardial cells in E15 hearts (Figure 1C and 1G). This staining confirmed the infectivity of all viruses. Thus, maintenance of normal Tbx5 expression in the chick PEO is required for proper development of the epicardium and coronary vasculature.

\section{Tbx5 Contributes to Chick Epicardial Cell Fate and Coronary Artery Development}

To determine whether Tbx5 activity during coronary vasculogenesis is required in the epicardium independent of its activity in the PEO, we used retroviral-mediated transgenesis to augment or knock down Tbx5 in the nascent epicardium in vivo directly. We microinjected either the same retroviruses as described above or control retrovirus encoding $\beta$-galactosidase (CXIZ) and TBX5-CXIZ retrovirus ${ }^{27}$ (Online Figure IIA) into the pericardial space (Online Figure IIB) at later stages of development (E4) when the epicardium had largely already formed. This produces transgenesis of the nascent epicardium (Figure 1I-1P). Because epicardium formation was not fully completed at this stage, areas of naked myocardium were exposed to viruses with this strategy, and the presence of infected myocardium in each embryo provided a positive control for viral infectivity. $\beta$-galactosidasepositive cells demonstrated infectivity of the epicardium at 8 (Figure 1I) and 24 hours (Figure 1J) after injection for all viruses. By 11 days after injection, $\beta$-galactosidase-positive cells were visible in the coronary blood vessels of most E15 CXL- and CXIZ-injected control embryos (21/23 CXL embryos; Figure 1K and 1L; 22/23 CXIZ embryos [not shown]). Altered embryonic epicardial Tbx5 expression (knockdown with cTbx5As-CXL [1/15 embryos]; Figure $1 \mathrm{M}$ and $1 \mathrm{~N}$ ) or overexpression with TBX5-CXIZ (0/18 embryos; Figure 10 and 1P) inhibited incorporation of infected cells into the coronary vasculature. These hearts displayed only sparse and patchy $\beta$-galactosidase-positive cells in the myocardium and
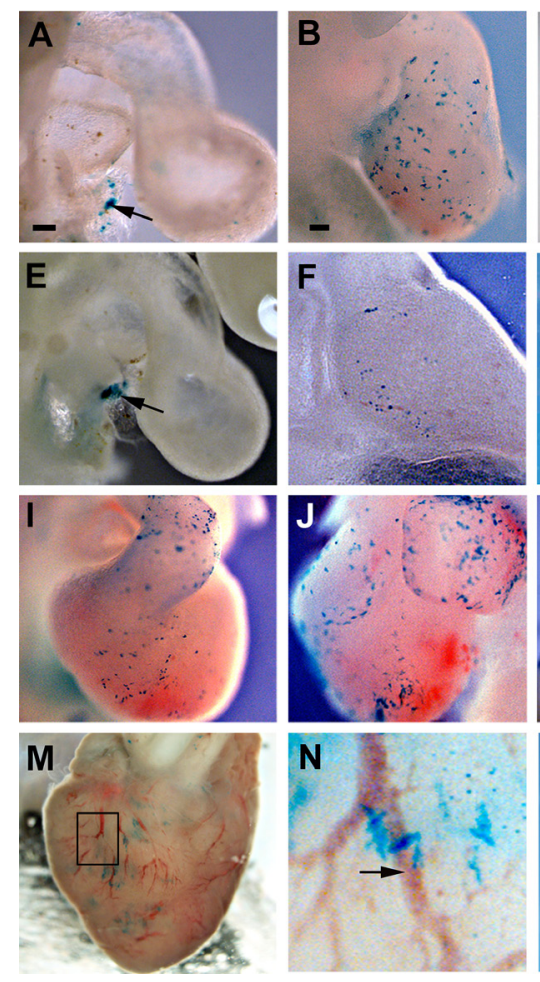
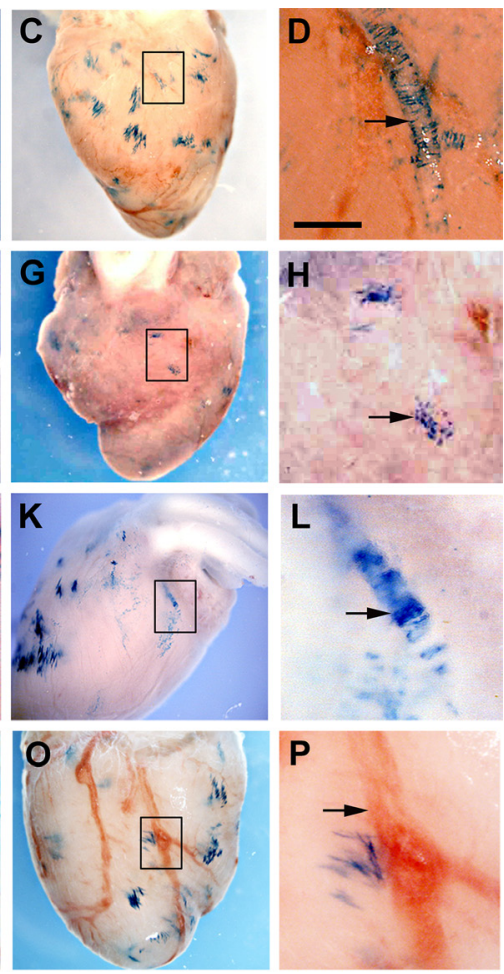

Figure 1. Knockdown and overexpression of Tbx5 affects proepicardial organ (PEO) cell development. A-P, Retroviral-mediated manipulation of $T b x 5$ gene dosage in ovo. $\beta$-galactosidase activity in whole mount hearts at 8 hours $(\mathbf{A}, \mathbf{E}, \mathbf{I}), 24$ hours $(\mathbf{B}, \mathbf{F}, \mathbf{J})$, and at E15 (C, D, G, H, K-P) after either in ovo PEO retroviral microinjection at $\mathrm{HH} 16$ with control CXL (A-D) and cTbx5As-CXL $(\mathbf{E}-\mathbf{H})$ retroviruses or in ovo epicardial infection at $\mathrm{HH} 23$ with control CXL (I-L), cTbx5As-CXL (M and $\mathbf{N}$ ) and TBX5-CXIZ (O and P) retroviruses. Arrows indicate $\beta$-galactosidasepositive PEO cells (A and $\mathbf{E})$, epicardial cells $(\mathbf{H})$, and also coronary vessels with ( $\mathbf{D}$ and $\mathbf{L}$ ) or without $(\mathbf{N}$ and $\mathbf{P}) \beta$-galactosidase activity. Scale bars, $100 \mu \mathrm{m}(\mathbf{A}-\mathbf{P})$. 
epicardium (Figure $1 \mathrm{~N}$ and $1 \mathrm{P}$ ). Thus, maintenance of normal Tbx 5 dosage in the epicardium is required for its proper maturation and the subsequent incorporation of EPDCs into coronary blood vessels.

To investigate cellular mechanisms underlying impaired epicardial cell development, we examined the effect of cTbx 5 augmentation on in vitro PEO cell behavior. We previously demonstrated that in vitro TBX5 overexpression in PEO explants impaired migration of proepicardial cells out of these TBX5-CXIZ-infected PEO explants but did not affect PEO cell proliferation. ${ }^{16}$ In addition to our previous observations, we now detect some apoptotic migratory proepicardial cells outside of the PEO explants (Online Figure IIID-IIIF). Apoptosis was not observed in control CXIZ-infected migratory proepicardial cells. Thus, in vitro augmentation of proepicardial cTbx5 not only impaired migration of proepicardial cells, but also caused apoptosis in some migratory proepicardial cells.

\section{Epicardial Inactivation of Murine Tbx5 Affects Formation and Maturation of the Epicardium and Migration of EPDCs}

In the mouse, ubiquitous deletion of $m T b \times 5$ caused embryonic lethality by E10.5 that previously precluded analysis of coronary vasculogenesis. ${ }^{21}$ We circumvented this barrier by conditional tissue-specific ablation of $T b \times 5$ in the proepicardium and its derivatives. We crossed C57B1/6 female Tbx5 conditional knockout mice $\left(T b x 5^{\text {lox/lox }}\right)^{21}$ with $\mathrm{C} 57 \mathrm{Bl} / 6$ male $\mathrm{Wt1}$ Cre driver mice that express Cre-recombinase in proepicardial and epicardial cells. ${ }^{8,22}$ Male progeny ( $T b x 5^{\text {epi+/- }}$ ) exhibiting excision of 1 Tbx5 floxed allele and carrying the Cre transgene were crossed against female $T b x 5^{\text {lox/lox }}$ to generate mice with 2 floxed alleles excised in proepicardial cells, and hereafter referred to as $T b x 5^{l o x / l o x}$; Wt1-Cre $\left(T b x 5^{\text {epi- }}\right)$. We confirmed Cre-mediated deletion of Tbx5 and diminished Tbx5 mRNA expression in proepicardial cells of $T b x 5^{\text {epi-/ }}$ versus wild-type control mice (Online Figure IVA-IVE). Tbx $x 5^{\text {epi-r }}$ mice were born at significantly reduced Mendelian ratios compared with control mice $(P=0.03$; Online Figure IVF).

We analyzed $T b x 5^{\text {epi- }}$ embryos at various developmental stages to gain insight into the cause of lethality. Examination of whole mount and sectioned hearts from E9.5 wild-type and mutant mice revealed that both wild-type (Figure $2 \mathrm{~A}$ and 2B) and $T b x 5^{\text {epi- }}$ (Figure 2D and 2E) embryos form a proepicardium and express the proepicardial and epicardial cell marker, Wt1, in the proepicardium at E9.5 (Figure 2C and $2 \mathrm{~F})$. Although proepicardium specification appeared normal in $T b x 5^{\text {epi- }}$ embryos, mutant proepicardiums (Figure 2D-2F) often appeared smaller relative to wild-type proepicardiums (Figure 2A-2C). Analyses of in vivo cell behavior by Ki-67 immunostaining (Online Figure VA-VD) and terminal deoxynucleotidyl transferase dUTP nick end labeling (not shown) revealed unmodified rates of proliferation (Online Figure VE), and no evidence of increased apoptosis, respectively, in Tbx $5^{\text {epi-/ }}$ proepicardial cells was observed. Furthermore, our examination of proepicardial cell polarity in these embryos did not reveal altered expression or localization of apical (PAR3, ezrin), basolateral ( $\alpha 4$-integrin), and cell-cell junctional (ZO1) markers ${ }^{28}$ between wild-type and mutant proepicardiums at

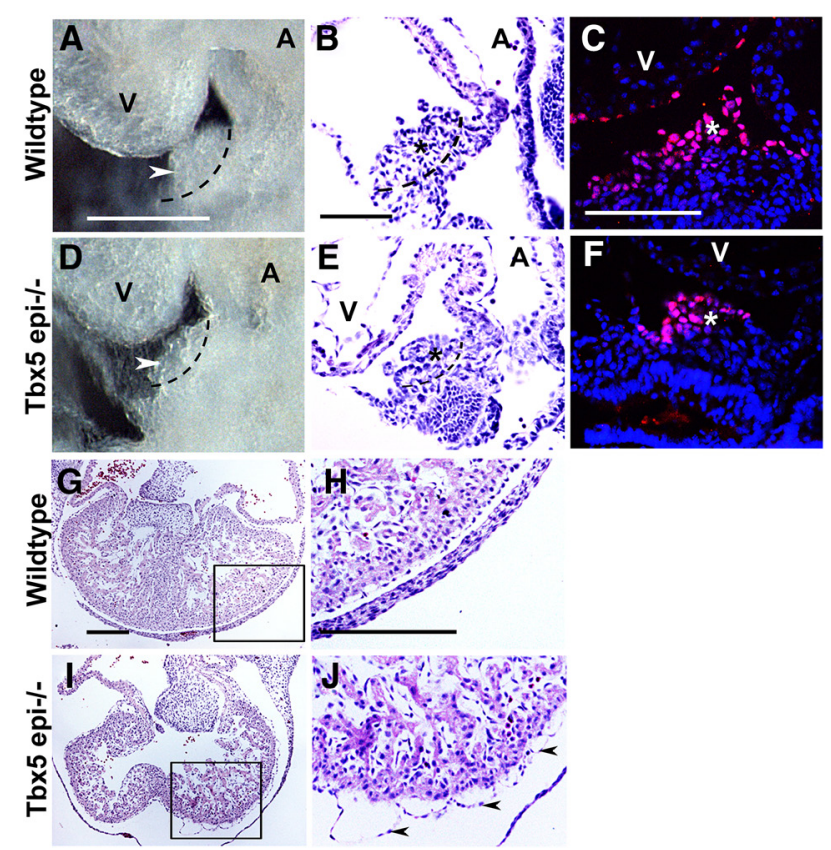

Figure 2. Phenotypic characterization of E9.5 Tbx5 $5^{\text {epi-/- }}$ embryos. A-F, Representative images of whole mount and sectioned E9.5 embryos. Whole mount wild-type (A) and Tbx5 $5^{\text {epi-- }}$ mutant (D) embryos. Hematoxylin and eosin (H\&E)-stained sections of wild-type (B) and Tbx $5^{\text {epi-l- }}$ mutant $(\mathbf{E})$ embryos. Immunofluorescent detection of Wt1 (pink) in sectioned wildtype (C) and Tbx5 $5^{\text {epi-r }}$ (F) hearts. Nuclei counterstained with 4,6-diamidino-2-phenylindole (blue). Scale bars, $500 \mu \mathrm{m}$ (A and D) and $100 \mu \mathrm{m}$ (B and E). Arrowheads (A and D) and asterisks (B, C, E, F) indicate proepicardium outlined by dashes. G-J, H\&E-stained sections of E11.5 wild-type ( $\mathbf{G}$ and $\mathbf{H})$ and Tbx5 ${ }^{\text {epi-l- }}$ (I and J) hearts. Arrowheads indicate epicardium. Scale bar, 200 $\mu \mathrm{m}(\mathbf{G}-\mathbf{J})$. A indicates atrium; and V, ventricle.

E9.5. These data indicated that Tbx5 deficiency did not alter proepicardial cell proliferation, apoptosis, or polarity.

The epicardial cell layer, as indicated by Wt1-positive cells, began to form on the myocardial surface of E10.5 wild-type and $T b \times 5^{\text {epi-r }}$ hearts (not shown). Although a smooth-surfaced epicardium was observed in E11.5 wild-type hearts (Figure $2 \mathrm{G}$ and $2 \mathrm{H}$ ), the epicardium in $T b x 5^{\text {epi- }}$ hearts appeared irregular and ruffled with focal regions that were unattached to the myocardium (Figures 2I and 2J). However, Wt1-positive epicardial cells were attached to the myocardium in both wild-

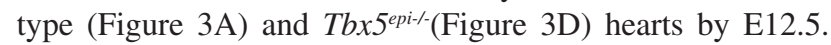
These data indicate that deletion of $T b x 5$ delayed adhesion of the epicardial cell layer to the myocardium, and Tbx 5 is important for proper structural formation of the epicardium.

Within the subepicardial space of E13.5 wild-type and mutant hearts, Wt1-positive epicardial cells began to delaminate and EPDCs began invading the compact myocardium (Figure 3B and 3E). Nonetheless, fewer Wt1-positive EPDCs invaded the compact myocardium of E13.5 mutant hearts (Figure 3E). We observed focal accumulation of Wt1-positive cells in the subepicardium of E14.5 mutant embryos (Figure 3F) when compared with wild-type littermates (Figure 3C). Quantification of these cells in the compact myocardium of E14.5 mice revealed a $48.5 \%$ reduction in Wt1-positive EPDCs in $T b \times 5^{\text {epi-- }}$ hearts versus wild-types (Figure $3 \mathrm{G}$ ). Thus, Tbx5 is important for proper EPDC migration. 

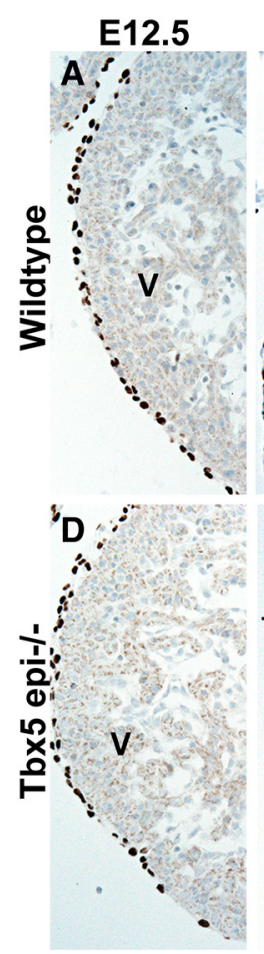

E13.5
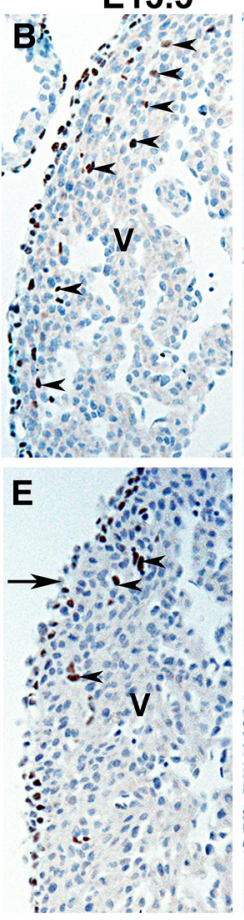

E14.5
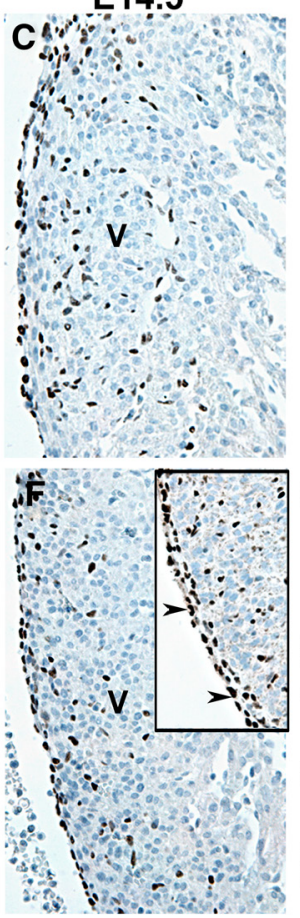

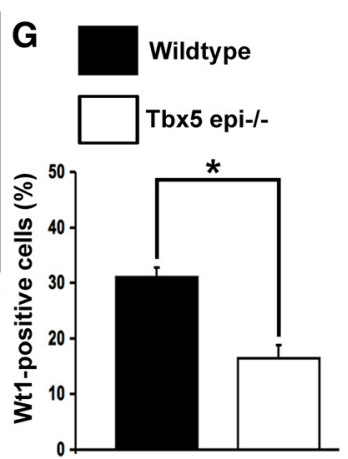

Figure 3. Altered migration of epicardial-derived cells into the myocardium of Tbx5 $5^{\text {epi-// }}$ hearts. A-F, Immunohistochemical detection of Wt1positive epicardial cells (brown) in wildtype (A-C) and Tbx5 ${ }^{\text {epi-l- }}$ (D-F) sectioned embryonic hearts at E12.5 (A and D), E13.5 (B and F), and E14.5 (C and F). Nuclei counterstained with hematoxylin (blue). Scale bars, $100 \mu \mathrm{m}$. Arrowheads denote Wt1-positive cells in the ventricle and epicardium. G, Quantification of Wt1positive cells in the compact myocardium of E14.5 wild-type (black bar; $n=4$ ) and $T b \times 5^{\text {epi-l }}$ (white bar; $n=4$ ) hearts. Data represented as mean \pm SEM. ${ }^{*} P<0.05$ vs wild-type. $V$ indicates ventricle.
Migration of EPDCs into the myocardium occurs in a patterned manner that involves several mechanisms, including epicardial cell proliferation, survival, ${ }^{29,30}$ and EMT. ${ }^{31,32}$ Despite the absence of altered proepicardial cell proliferation in E9.5 Tbx5 $5^{\text {epi- }}$ embryos, we observed a $42 \%$ reduction in $\mathrm{Ki}-67-$ positive proliferating epicardial cells in E12.5 Tbx5 $5^{\text {epi-- }}$ embryos (Figure 4E and 4I) when compared with wild-types (Figure 4A and 4I). Examination of these hearts for potential
EMT defects induced by proepicardial-specific deletion of Tbx5 did not reveal significant changes in the expression of the EMT markers Slug, Snail, and E-cadherin in E14.5 mutant versus wild-type embryos (not shown). These data demonstrate that proepicardial loss of $T b x 5$ produces developmental defects in the epicardium and EPDCs that may be precipitated by delayed epicardial cell adhesion to the myocardium and partially attributed to a reduction in epicardial cell proliferaton.

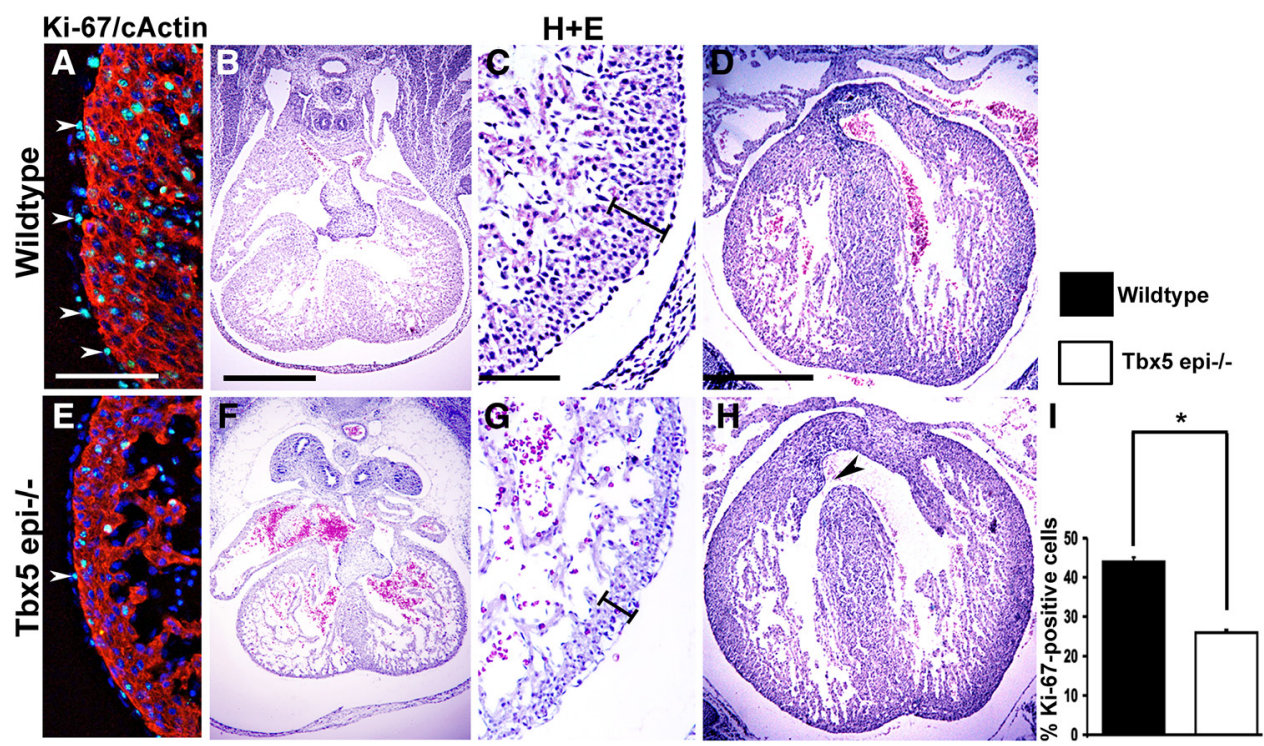

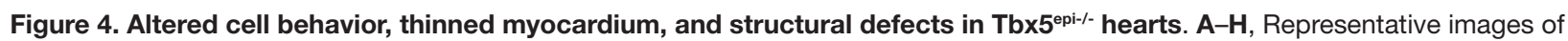
sectioned hearts. Immunofluorescent detection of Ki-67 (green) and cardiac actin (red) in E12.5 wild-type (A) and Tbx $5^{\text {epi-- }}$ (E) hearts. Nuclei counterstained with 4,6-diamidino-2-phenylindole. Hematoxylin and eosin (H+E)-stained sections in E12.5 (B, C, F, G) or E15.5 (D and $\mathbf{H})$ wild-type $(\mathbf{A}-\mathbf{D})$ and $T b x 5^{\text {epi-- }}(\mathbf{E}-\mathbf{H})$ hearts. Myocardial wall thickness indicated by brackets. Arrowhead indicates epicardium (A and E) or ventricular septal defect $\mathbf{( H )}$. I, Quantification of Ki-67-positive epicardial cells in wild-type (black bar; $\mathrm{n}=4$ ) and Tbx5 ${ }^{\text {epi-l- }}$ (white bar; $\mathrm{n}=4$ ) hearts. Scale bars, $100 \mu \mathrm{m}(\mathbf{A}, \mathbf{C}, \mathbf{E}, \mathbf{G})$ and $500 \mu \mathrm{m}(\mathbf{B}, \mathbf{F}, \mathbf{D}, \mathbf{H})$. Data represented as mean+SEM. ${ }^{*} P<0.05$ vs wild-type. 


\section{Structural Defects and Impaired Cardiac Growth in Tbx5 ${ }^{\text {epi- } / \text { Mice }}$}

We did not observe gross morphological differences in whole mount embryos or hearts from E12.5 wild-type and Tbx $5^{\text {epi-- }}$ mice. Normal formation of the compact myocardium was observed in hematoxylin and eosin-stained wild-type E12.5 hearts (Figure 4B and 4C). However, we observed a thinned compact myocardium in E12.5 Tbx $5^{\text {epi- }}$ mice (Figure 4F and $4 \mathrm{G}$ ) in comparison with wild-type littermates. A comparison of Ki-67-positive cardiomyocytes in E12.5 wild-type versus mutant mouse hearts revealed a $48 \%$ reduction in cardiomyocyte proliferation in $\mathrm{Tb} 5^{\text {epi-/ }}$ hearts when compared with wild-type hearts (not shown). Terminal deoxynucleotidyl transferase dUTP nick end labeling assays of sectioned hearts did not reveal myocardial apoptosis in the hearts of E12.5 wild-type or $T b x 5^{\text {epi- }}$ embryos. However, myocardial apoptosis was observed in E14.5 mutant hearts when compared with wild-types (not shown). In contrast to wild-type hearts (Figure 4D), muscular and membranous ventricular septal defects were seen in $15 \%$ of E15.5 Tbx5 $5^{\text {epi- }}$ embryos (Figure $4 \mathrm{H}$ ). Collectively, these myocardial defects may result from both a decrease in myocardial cell proliferation and the onset of cardiomyocyte apoptosis secondary to impaired epicardial formation and EPDC development in $T b x 5^{\text {epi-r }}$ embryos.

\section{Epicardial Inactivation of Tbx5 Affects Development of the EPDCs and Coronary Vasculogenesis}

Gross inspection of E15.5 wild-type and Tbx5 $5^{\text {epi-/ }}$ mice revealed areas of peripheral hemorrhage in mutant embryos (Online Figure VIE) that was not observed in wild-type littermates (Online Figure VIA). Overall cardiac patterning was similar in both wild-type and mutant mice, but ventricular chamber size appeared to be reduced in $T b x 5^{\text {epi- }}$ versus wildtype embryos. In contrast to E15.5 wild-type hearts (Online Figure VIB), Tbx $5^{\text {epi-/ }}$ hearts exhibited punctate areas of hemorrhaging (Online Figure VIF). Histology revealed abnormal vascular structures in mutant hearts. As opposed to E15.5 wild-type hearts (Online Figure VIC), Tbx $5^{\text {epi-/ }}$ hearts exhibited epicardial cyst-like structures lined by delaminated epicardium that were filled with erythrocytes (Online Figure VIG). Platelet endothelial cell adhesion molecule-1 immunostaining revealed a subepicardial accumulation of vessels in mutant hearts (Online Figure VIH) compared with wild-types (Online Figure VID). Together, these data are indicative of a coronary vascular defect in $T b x 5^{\text {epi-r- }}$ hearts.

Given that EPDCs differentiate into SMCs, cardiac fibroblasts, and endothelial cells, , $^{1,7,8}$ we determined the effects of proepicardial-specific deletion of $T b \times 5$ on these cell populations. Histological analysis of E17.5 wild-type and Tbx5 $5^{\text {epi- }}$ hearts revealed nests of multiple contiguous subepicardial vessel-like structures that did not penetrate the myocardium of mutant hearts (Figure 5E) in contrast to wild-type hearts (Figure 5A). We determined that SMC recruitment to nascent coronary vessels was affected in $T b x 5^{\text {epi- }}$ hearts via immunohistochemical analysis for SMC-specific protein (SM22 $\alpha$ ). SMCs formed a continuous layer surrounding the coronary vessels of E17.5 wild-type hearts (Figure 5B), whereas the SMC layer was either completely lost or discontinuous throughout the coronary vessels of $T b x 5^{\text {epi-/ }}$ hearts (Figure 5F). Immunostaining for periostin, a marker of the noncardiomyocyte lineage that is enriched in cardiac fibroblasts, revealed a reduced fibroblast invasion of the cardiac interstitium in E17.5 Tb $\times 5^{\text {epi- }}$ hearts (Figure 5G) when compared with wild-types (Figure 5C). Platelet endothelial cell adhesion molecule-1 (CD31) immunostaining revealed an elaborate ventricular capillary network in wild-type (Figure 5D) and Tbx $x 5^{\text {epi-- }}$ hearts (Figure 5H). However, subsequent vessel quantification revealed a $45 \%$ reduction in platelet endothelial cell adhesion molecule-1-positive capillary density in $T b \times 5^{\text {epi-l }}$ hearts compared with wild-type hearts (Figure $5 \mathrm{M}$ ). Together, these results suggest that a partial defect occurred during coronary vascular maturation in $T b x 5^{\text {epi-/ }}$ hearts that affected SMC recruitment and caused reductions in formation of endothelial cells and other noncardiomyocytes that may include cardiac fibroblasts.

We sought to determine the physiological manifestations of these vascular developmental anomalies. In fact, we observed hypoxia in $T b x 5^{\text {epi- }}$ mice. Compared with wild-type hearts (Figure 5I and 5J), E18.5 Tbx5 $5^{\text {epi- }}$ hearts displayed increased immunoreactivity for hypoxia inducible factor- $1 \alpha$ (Figure 5K), as well as increased binding of hypoxyprobe-1 (pimonidazole hydrochloride; Figure 5L), respectively. Hypoxyprobe-1 forms protein adducts in cells with a $\mathrm{PO}_{2}<10 \mathrm{mmHg}$. To determine the physiological consequences of this myocardial relative hypoxic state, we evaluated the maximal exercise capacity of $T b x 5^{\text {epi- }}$ mice. Twelve- to 16 -weekold $T b x 5^{\text {epi-/ }}$ mice were subjected to graded treadmill exercise testing. ${ }^{33}$ In contrast to wild-type mice, $T b x 5^{\text {epi-/ }}$ mice exhibited a significantly reduced maximal exercise tolerance (Figure $5 \mathrm{~N}$ ).

\section{Transcriptome Analysis of Wild-Type and Tbx5 $5^{\text {epi-l- }}$ Mouse Hearts}

To gain insight into Tbx5-dependent molecular pathways involved in epicardial and EPDC development during coronary vasculogenesis, we characterized the transcriptome

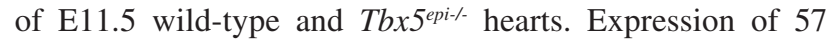
genes was dysregulated in $T b \times 5^{\text {epi- }}$ hearts $(P<0.05)$. Among these dysregulated genes, $91.2 \%$ were downregulated and $8.8 \%$ were upregulated in $T b \times 5^{\text {epi-/ }}$ versus wild-type hearts (Figure 6A). Gene ontology analysis of significantly downregulated transcripts in $T b \times 5^{\text {epi- }}$ mouse hearts revealed dysregulation of genes involved in vitamin A biosynthesis, cell adhesion, enhancer binding, RNA polymerase II transcriptional activity, and developmental growth (Figure 6B). Genes encoding these biological functions, which correlate to retinoic acid signaling, gene transcription, development, and cell-cell interactions, contribute to epicardial and EPDC development. ${ }^{1,2,29,34-36}$ We previously observed focal regions of irregular, ruffled epicardium that were unattached to the myocardium in E11.5 Tbx $55^{\text {epi- }}$ hearts, but became attached by E12.5. Because changes in expression of cell adhesion and extracellular matrix (ECM) proteins could contribute to such abnormal epicardial integrity, we used quantitative reverse transcriptase-polymerase chain reaction to validate mRNA expression of the Ajap1, Frem3, and Reln genes encoding these cell adhesion and ECM proteins. ${ }^{37-39}$ Expression of these genes was significantly decreased in epicardial cells and EPDCs of E11.5 mutant versus wild-type hearts (Figure 6C) 

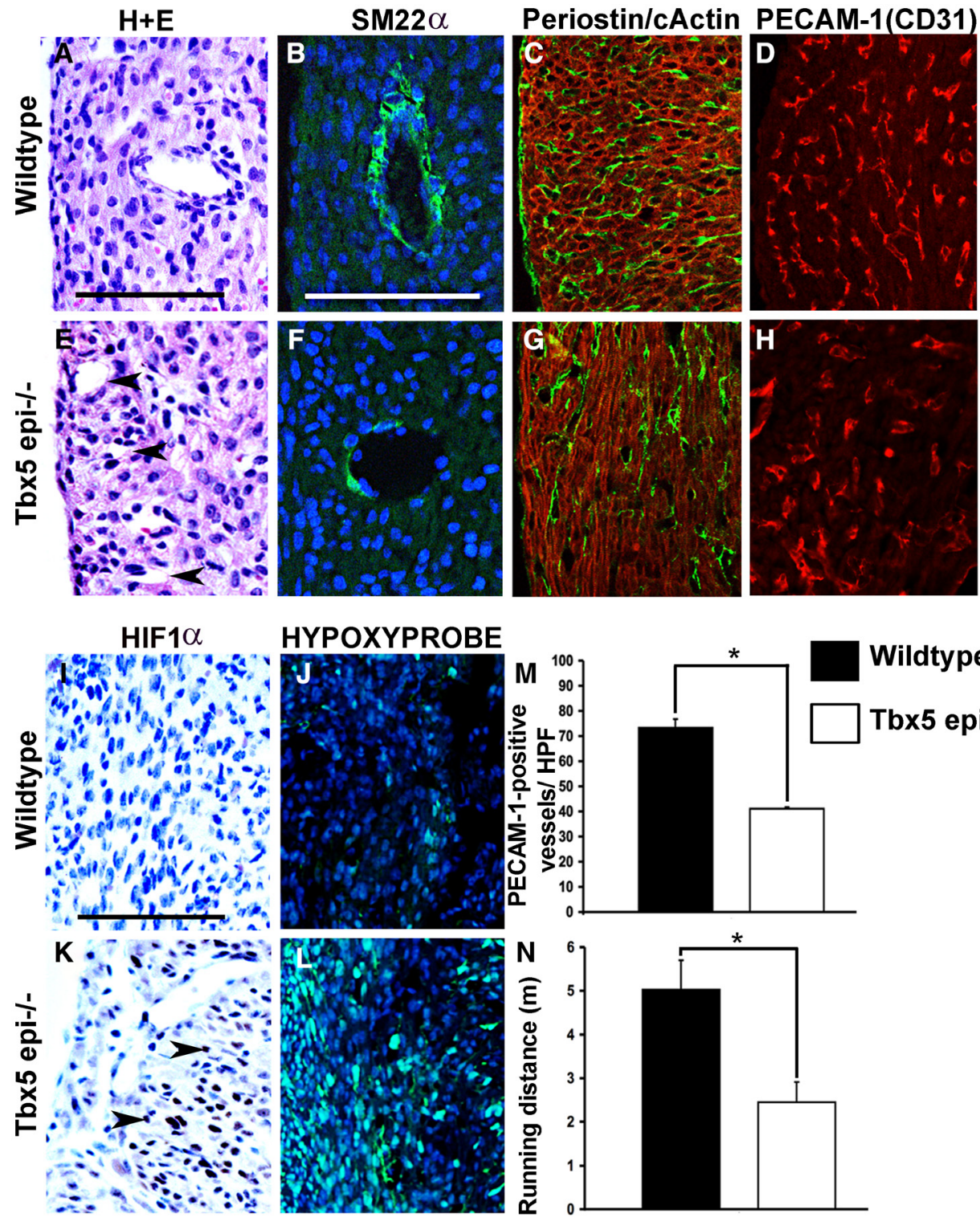

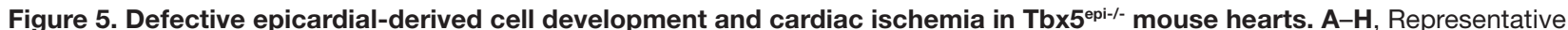
images of Hematoxylin and eosin ( $\mathrm{H}+\mathrm{E})$-stained $(\mathbf{A}$ and $\mathbf{E})$ and immunofluorescently stained sections of E17.5 wild-type (A-D) and Tbx5 ${ }^{\text {epi-/ }}(\mathbf{E}-\mathbf{H})$ sectioned hearts. Immunofluorescent detection of the smooth muscle cell-specific protein (SM22 $\alpha$; $\mathbf{B}$ and $\mathbf{F}$, green), periostin ( $\mathbf{C}$ and $\mathbf{G}$, green), cardiac actin (C and $\mathbf{G}$, red), and platelet endothelial cell adhesion molecule-1 (PECAM-1)/CD31 (D and $\mathbf{H}$, red). Nuclei couterstained with 4,6-diamidino-2-phenylindole (DAPI; B and F, blue). I-L, hypoxia inducible factor-1 $\alpha$ (HIF1 $\alpha$ ) immunostaining (dark brown) of E18.5 wild-type (I) and Tbx5 epi-- (K) sectioned hearts. Nuclei counterstained with hematoxylin (blue). Hypoxyprobe-1 binding (green) on sectioned E18.5 wild-type (J) and Tbx5 $5^{\text {epi-r- }}$ mutant (L) hearts. Nuclei counterstained with DAPI (blue). M, Quantification of PECAM-1-positive vessels/high-powered field (HPF) in E17.5 wild-type (black bar; $\mathrm{n}=4$ ) and Tbx5 $5^{\text {epi-r- }}$ (white bar; $\mathrm{n}=4$ ) hearts. Data represent mean+SEM. ${ }^{*} P<0.05$ vs wild-type. N, Absolute maximum exercise tolerance quantified in $12-$ to 16 -weekold adult wild-type (black bar; $n=6$ ) and $T b \times 5^{\text {epi-- }}$ (white bar; $n=10$ ) mice. Data represent mean $\pm S E M ;{ }^{*} P<0.05$ vs wild-type. Scale bars, $100 \mu \mathrm{m}(\mathbf{A}-\mathbf{L})$.

and this may contribute to the delayed epicardial cell attachment to the myocardium in these hearts.

\section{Discussion}

In this study, we demonstrate a conserved requirement for Tbx5 in avian and mammalian proepicardial development, as well as epicardial and coronary vascular formation and maturation. We show that $T b x 5$ displays a dynamic expression pattern in embryonic proepicardial cell lineages and regulates development of chick and mouse epicardial and coronary vascular progenitor cells from the PEO and epicardium, respectively. Moreover, genetically engineered loss of $T b \times 5$ in the mouse proepicardium results in defective epicardial formation because of delayed epicardial cell adhesion to the myocardium and altered developmental gene expression. We believe that this consequently leads to impaired EPDC production and invasion into the myocardium, compromised establishment of the coronary vasculature, decreased myocardial growth and myocardial hypoxia, and reduced maximal exercise tolerance in $T b x 5^{\text {epi- }}$ mice. We conclude that Tbx5 is indispensable for 
A

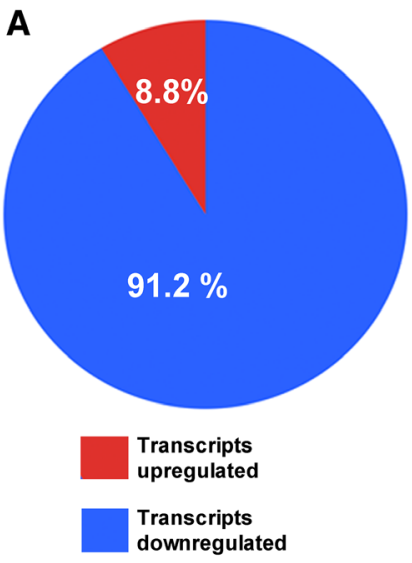

C

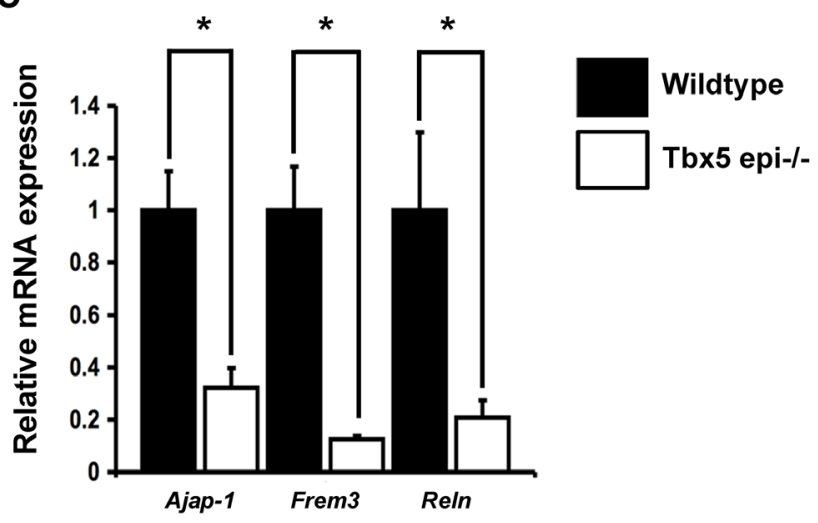

B

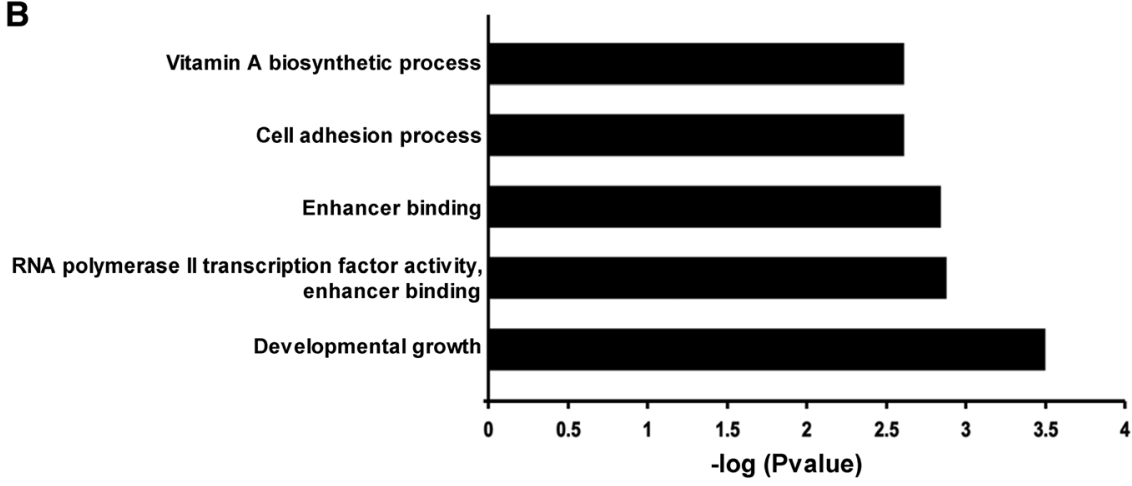

Figure 6. Altered cardiac gene expression with proepicardial-specific deletion of mouse Tbx5. A, Representation of the percentage of genes upregulated (red) or downregulated (blue) in hearts of E11.5 Tbx $5^{\mathrm{epi} i-}$ vs wild-type mice. B, Gene ontology analysis of significantly enriched biological processes displayed as -log base 10 ( $p$ value). C. Quantitative reverse transcriptase-polymerase chain reaction analysis of Ajap-1, Frem3, and Reln gene expression in epicardial cells and EPDCs of E11.5 wild-type (black bar; $\mathrm{n}=4)$ and $T b \times 5^{\text {epi-l- }}$ hearts (white bar; $n=4$ ). Data represent mean $\pm S E M,{ }^{*} P<0.05$ vs wild-type.

normal epicardial formation and coronary vasculogenesis during embryogenesis, and this requirement may be reflected in the pericardial agenesis and anomalous coronary arteries seen in human patients with HOS and defective TBX5 ${ }^{19,20}$

Loss of murine Tbx5 in the proepicardium did not prevent proepicardial cell specification and formation in $T b x 5^{\text {epi- }}$ mouse embryos as exhibited in zebrafish with mutant Tbx $5 .^{40}$ The genetically heterogeneous nature of the proepicardium was recently demonstrated to have molecularly distinct expression domains ${ }^{7}$ and our expression analyses similarly suggest that Tbx 5 expression is also heterogeneous throughout the developing proepicardium and epicardium. This may explain the normal specification and development of proepicardial cells in $T b x 5^{\text {epi-r }}$ embryos. We will further explore this heterogeneity of Tbx 5 expression in the proepicardium in future studies. Furthermore, we cannot exclude that other T-box transcription factors expressed in the proepicardium and EPDCs, such as Tbx $18^{15}$, may partially compensate for the Tbx 5 deficiency. Although proepicardial development is molecularly conserved across species ${ }^{40}$ we speculate that minor differences in Tbx 5 expression and function occur during proepicardial development across species. This was exemplified by the lack of a functionally conserved requirement for Tbx 5 between our embryonic chicks and mice in regulating proepicardial cell apoptosis. Although we observed some apoptotic migratory proepicardial cells outside of the TBX5-CXIZ-infected chick
PEO explants, we did not observe apoptotic proepicardial cells in $T b x 5^{\text {epi- }}$ mouse embryos. We speculate that apoptosis is an epiphenomenon of altered chick $T b x 5$ gene dose that reflects the untimely fate of proepicardial cells with augmented cell migratory behavior. This may partially explain the reduced incorporation of EPDCs into the coronary vessels of hearts from E15 cTbx5As-CXL or TBX5-CXIZ-injected chick embryos.

The epicardial cell layer formed in E11.5 Tbx $5^{\text {epi- }}$ mice. However, its structural integrity appeared defective as exhibited by an irregular, ruffled epicardium with focal regions that delayed attachment to the myocardium until E12.5. Transcriptome analysis of our E11.5 mouse hearts demonstrated that proepicardium-specific deletion of $T b \times 5$ altered several biological functions, including cell-cell interactions. Ajap 1, Frem3, and Reln, which encode cell adhesion and ECM proteins, were among the downregulated genes identified in our $T b x 5^{\text {epi-r }}$ mouse hearts. Epicardial cell adhesion to the myocardium is important for EPDC production and delamination into the subepicardial space, invasion into the myocar-

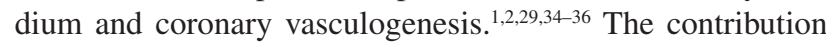
of these genes to cardiovascular development is unknown, but these structural adhesion molecules are known to mediate cell-cell interactions in extracardiac tissues ${ }^{37-39}$ and, thus, we have identified novel genes involved in a Tbx5-dependent pathway of epicardial development. We think that downregulation of these cell adhesion and ECM genes may contribute 
to the delayed epicardial cell attachment to the myocardium in $T b x 5^{\text {epi-l }}$ hearts. Proper establishment of epicardial structure provides the foundation for subsequent EPDC development, delamination into the subepicardial space and myocardial invasion to form coronary vessels. Thus, it is likely that the defective epicardial structure of our $T b x 5^{\text {epi- }}$ embryonic hearts precipitated the decrease in EPDC production, impaired myocardial migration of EPDCs, and also perturbed coronary vasculogenesis. These findings are reminiscent of the structural and functional defects observed during epicardium and coronary vascular development of proepicardium-specific Tbx18-deficient mice, which similarly exhibited an irregular epicardial surface with frequent areas distended from the myocardium, as well as subepicardial nodules containing erythroblasts. ${ }^{15}$ EPDC invasion of the myocardium involves several mechanisms, including epicardial cell proliferation, survival, ${ }^{29,30}$ and EMT. ${ }^{31,32}$ Although expression of EMT and apoptotic markers was unaffected by proepicardium-specific deletion of Tbx5 in our mice, epicardial cell proliferation was significantly reduced in E12.5 Tbx $5^{\text {epi- }}$ embryos. Tbx5 has been previously shown to regulate cell proliferation during morphogenesis of tissues, including the vertebrate heart. ${ }^{27,41}$ The diminished epicardial cell proliferation observed in our mutant mice may underlie the impaired production of EPDCs given that epicardial cell proliferation is intricately linked to EPDC invasion of the myocardium. ${ }^{30,42}$ Thus, we think that the impaired EPDC development in our Tbx $5^{\text {epi- }}$ embryos is a consequence of a suboptimal environment previously established by delayed epicardial cell adhesion to the myocardium and this is compounded by reduced epicardial cell proliferation. The resultant inability of EPDCs to invade the myocardium is consistent with previous reports of altered deposition of adhesion molecules during mammalian cardiogenesis that hindered EPDC migration into the ventricular myocardium. ${ }^{29,34,43,44}$ Altogether, these data indicate that Tbx5 expression is critical for establishing normal epicardial structure and subsequent EPDC production.

EPDCs contribute to the formation of SMCs, endothelial cells, and cardiac fibroblasts in avian and murine hearts during coronary vasculogenesis..$^{1,2,7,45}$ In fetal $T b x 5^{\text {epi- }}$ mouse hearts, we observed impaired SMC recruitment and a reduction in endothelial cells and cardiac fibroblasts. Our data demonstrate that impaired development of these lineages subsequently leads to abnormal coronary vasculogenesis in $T b x 5^{\text {epi-/ }}$ hearts. Further analysis will need to be performed to determine whether Tbx 5 acts directly or indirectly to influence differentiation of these lineages. However, we speculate that delayed epicardial cell attachment to the myocardium precipitates a cascade of events that lead to abnormal coronary vasculogenesis in $T b x 5^{\text {epi-/ }}$ hearts. Our data collectively support a model in which proepicardium-specific Tbx5 deficiency inhibits expression of cell adhesion and ECM proteins and delays epicardial cell attachment to the myocardium to disrupt epicardium integrity. The epicardium defect is made worse by reduced epicardial cell proliferation. As a result, EPDC production, delamination into the subepicardial space, and myocardial invasion are impaired. Together, these events contribute to abnormal coronary vasculogenesis in $T b x 5^{\text {epi-/ }}$ embryos. In addition, $T b x 5^{\text {epi-/ }}$ mice exhibit hypoplastic ventricular trabeculation and $15 \%$ of mice display ventricular septal defects consistent with paracrine effects of the epicardium on stimulating myocardial growth and development. To our knowledge, $T b x 5^{\text {epi-/ }}$ mice represent the first proepicardium-specific deletion mouse model to exhibit cardiac septation defects. Atrial septal defects caused by apoptosis or reduced cell proliferation were previously observed on $T b x 5$ deletion in the endocardium ${ }^{46}$ or posterior second heart field, ${ }^{41}$ respectively. Therefore, it is plausible that EPDCs display similar non cell-autonomous growth-promoting activities on the interventricular septum. In addition, our analysis of Wt1 expression in the developing mouse heart documented the presence of Wt1-positive EPDCs in the interventricular septum, and reports have raised the possibility that EPDCs may differentiate into cardiomyocytes in the interventricular septum. ${ }^{1,8}$ Thus, septation defects observed in mice with ubiquitous Tbx5 deficiency and in patients with HOS may result from reduced Tbx5 activity in the myocardium, as well as in the proepicardium and epicardium. ${ }^{19-21}$

Proepicardial-specific loss of Tbx5 in mice causes embryonic lethality that may result from cumulative effects on coronary vasculogenesis and epicardial cell growth and survival to, subsequently, impose myocardial growth defects that alter cardiac structure. Defective coronary vasculogenesis leads to ischemic cardiomyopathy in adult $T b x 5^{\text {epi-/ }}$ mice. These mice exhibit resting hypoxia and exercise-induced ischemia. It is not uncommon for human adults to present with poorly explained cardiomyopathy long after childhood repair of congenital heart malformations, and patients with HOS have been reported to develop diastolic ventricular dysfunction even after repair of septation defects. ${ }^{47}$ Ischemia is a well-recognized cause of reduced ventricular compliance, and thus subclinical microvascular hypoplasia in HOS may contribute to chronic ischemia and the late onset cardiomyopathy that has been observed. On the basis of our observations that augmentation of chick and murine Tbx5 affects proepicardial development, disrupts epicardial structural integrity, impairs EPDC development, and decreases vascular investment of the myocardium, we conclude that $T b \times 5$ is indispensable for normal epicardial and coronary vascular formation during embryogenesis. This requirement for $T b \times 5$ in mouse and chick epicardial development may be reflected in the pericardial agenesis and anomalous coronary arteries seen in human patients with HOS and defective TBX5. ${ }^{19,20}$ Additional studies will determine the combined effects of epicardial and myocardial Tbx 5 activity to dissect pathways in normal cardiogenesis and the phenotypes of patients with HOS.

\section{Acknowledgments}

This article is dedicated to the memory of our respected colleague and friend, Dr Nata Diman, who passed away on March 20, 2014. We gratefully acknowledge his contribution to this study and his passion for science.

\section{Sources of Funding}

This work was supported by grants from National Institutes of Health (K01 HL080948 [C.J. Hatcher], R01 HL80663 [C.T. Basson], RC1 HL100579 [C.T. Basson, C.J. Hatcher], and 5U01HL098166 [J.G. Seidman and C.E. Seidman]), the Snart Cardiovascular Fund (C.J. Hatcher), Raymond and Beverly Sackler (C.J. Hatcher), and the Center for Chronic Disorders of Aging (C.J. Hatcher). 


\section{Disclosures}

None.

\section{References}

1. Olivey HE, Svensson EC. Epicardial-myocardial signaling directing coronary vasculogenesis. Circ Res. 2010;106:818-832.

2. Pérez-Pomares JM, de la Pompa JL. Signaling during epicardium and coronary vessel development. Circ Res. 2011;109:1429-1442.

3. Kovacic JC, Mercader N, Torres M, Boehm M, Fuster V. Epithelial-tomesenchymal and endothelial-to-mesenchymal transition: from cardiovascular development to disease. Circulation. 2012;125:1795-1808.

4. Tian X, Hu T, Zhang H, et al. Subepicardial endothelial cells invade the embryonic ventricle wall to form coronary arteries. Cell Res. 2013;23:1075-1090.

5. Red-Horse K, Ueno H, Weissman IL, Krasnow MA. Coronary arteries form by developmental reprogramming of venous cells. Nature. 2010;464:549-553.

6. Wu B, Zhang Z, Lui W, Chen X, Wang Y, Chamberlain AA, MorenoRodriguez RA, Markwald RR, O'Rourke BP, Sharp DJ, Zheng D, Lenz J, Baldwin HS, Chang CP, Zhou B. Endocardial cells form the coronary arteries by angiogenesis through myocardial-endocardial VEGF signaling. Cell. 2012;151:1083-1096.

7. Katz TC, Singh MK, Degenhardt K, Rivera-Feliciano J, Johnson RL, Epstein JA, Tabin CJ. Distinct compartments of the proepicardial organ give rise to coronary vascular endothelial cells. Dev Cell. 2012;22:639-650.

8. Wessels A, van den Hoff MJ, Adamo RF, Phelps AL, Lockhart MM, Sauls K, Briggs LE, Norris RA, van Wijk B, Perez-Pomares JM, Dettman RW, Burch JB. Epicardially derived fibroblasts preferentially contribute to the parietal leaflets of the atrioventricular valves in the murine heart. Dev Biol. 2012;366:111-124.

9. Christoffels VM, Grieskamp T, Norden J, Mommersteeg MT, Rudat C, Kispert A. Tbx18 and the fate of epicardial progenitors. Nature. 2009;458:E8-9; discussion E9.

10. Lockhart MM, Phelps AL, van den Hoff MJ, Wessels A. The epicardium and the development of the atrioventricular junction in the murine heart. $J$ Dev Biol. 2014;2:1-17.

11. Choi WY, Poss KD. Cardiac regeneration. Curr Top Dev Biol. 2012;100:319-344.

12. Acharya A, Baek ST, Huang G, Eskiocak B, Goetsch S, Sung CY, Banfi S, Sauer MF, Olsen GS, Duffield JS, Olson EN, Tallquist MD. The bHLH transcription factor Tcf21 is required for lineage-specific EMT of cardiac fibroblast progenitors. Development. 2012;139:2139-2149.

13. Braitsch CM, Combs MD, Quaggin SE, Yutzey KE. Pod1/Tcf21 is regulated by retinoic acid signaling and inhibits differentiation of epicardium-derived cells into smooth muscle in the developing heart. Dev Biol. 2012;368:345-357.

14. Baek ST, Tallquist MD. Nf1 limits epicardial derivative expansion by regulating epithelial to mesenchymal transition and proliferation. Development. 2012;139:2040-2049.

15. Wu SP, Dong XR, Regan JN, Su C, Majesky MW. Tbx18 regulates development of the epicardium and coronary vessels. Dev Biol. 2013;383:307-320.

16. Hatcher CJ, Diman NY, Kim MS, Pennisi D, Song Y, Goldstein MM, Mikawa T, Basson CT. A role for Tbx5 in proepicardial cell migration during cardiogenesis. Physiol Genomics. 2004;18:129-140.

17. Basson CT, Bachinsky DR, Lin RC, Levi T, Elkins JA, Soults J, Grayzel D, Kroumpouzou E, Traill TA, Leblanc-Straceski J, Renault B, Kucherlapati R, Seidman JG, Seidman CE. Mutations in human TBX5 [corrected] cause limb and cardiac malformation in Holt-Oram syndrome. Nat Genet. 1997; 15:30-35.

18. Li QY, Newbury-Ecob RA, Terrett JA, et al. Holt-Oram syndrome is caused by mutations in tbx 5 , a member of the brachyury ( $\mathrm{t}$ ) gene family. Nat Genet. 1997;15:21-29.

19. Dias RR, Albuquerque JM, Pereira AC, Stolf NA, Krieger JE, Mady C, Oliveira SA. Holt-Oram syndrome presenting as agenesis of the left pericardium. Int J Cardiol. 2007;114:98-100

20. Vianna CB, Miura N, Pereira AC, Jatene MB. Holt-Oram syndrome: novel TBX5 mutation and associated anomalous right coronary artery. Cardiol Young. 2011;21:351-353.

21. Bruneau BG, Nemer G, Schmitt JP, Charron F, Robitaille L, Caron S, Conner DA, Gessler M, Nemer M, Seidman CE, Seidman JG. A murine model of Holt-Oram syndrome defines roles of the T-box transcription factor Tbx5 in cardiogenesis and disease. Cell. 2001;106:709-721.

22. del Monte G, Casanova JC, Guadix JA, MacGrogan D, Burch JB, PérezPomares JM, de la Pompa JL. Differential Notch signaling in the epicardium is required for cardiac inflow development and coronary vessel morphogenesis. Circ Res. 2011;108:824-836.

23. Bimber B, Dettman RW, Simon HG. Differential regulation of Tbx5 protein expression and sub-cellular localization during heart development. Dev Biol. 2007;302:230-242.

24. Bruneau BG, Logan M, Davis N, Levi T, Tabin CJ, Seidman JG, Seidman CE. Chamber-specific cardiac expression of Tbx 5 and heart defects in Holt-Oram syndrome. Dev Biol. 1999;211:100-108.

25. Hatcher CJ, Goldstein MM, Mah CS, Delia CS, Basson CT. Identification and localization of TBX5 transcription factor during human cardiac morphogenesis. Dev Dyn. 2000;219:90-95.

26. Mikawa T, Fischman DA, Dougherty JP, Brown AM. In vivo analysis of a new lacZ retrovirus vector suitable for cell lineage marking in avian and other species. Exp Cell Res. 1991;195:516-523.

27. Hatcher CJ, Kim MS, Mah CS, Goldstein MM, Wong B, Mikawa T, Basson CT. TBX5 transcription factor regulates cell proliferation during cardiogenesis. Dev Biol. 2001;230:177-188.

28. Hirose T, Karasawa M, Sugitani Y, Fujisawa M, Akimoto K, Ohno $\mathrm{S}$, Noda T. PAR3 is essential for cyst-mediated epicardial development by establishing apical cortical domains. Development. 2006;133:1389-1398.

29. Barnes RM, Firulli BA, VanDusen NJ, Morikawa Y, Conway SJ, Cserjesi P, Vincentz JW, Firulli AB. Hand2 loss-of-function in Hand1-expressing cells reveals distinct roles in epicardial and coronary vessel development. Circ Res. 2011;108:940-949.

30. Wu M, Smith CL, Hall JA, Lee I, Luby-Phelps K, Tallquist MD. Epicardial spindle orientation controls cell entry into the myocardium. Dev Cell. 2010;19:114-125.

31. Martínez-Estrada OM, Lettice LA, Essafi A, Guadix JA, Slight J, Velecela V, Hall E, Reichmann J, Devenney PS, Hohenstein P, Hosen N, Hill RE, Muñoz-Chapuli R, Hastie ND. Wt1 is required for cardiovascular progenitor cell formation through transcriptional control of Snail and E-cadherin. Nat Genet. 2010;42:89-93.

32. von Gise A, Zhou B, Honor LB, Ma Q, Petryk A, Pu WT. WT1 regulates epicardial epithelial to mesenchymal transition through $\beta$-catenin and retinoic acid signaling pathways. Dev Biol. 2011;356:421-431.

33. Hernandez OM, Szczesna-Cordary D, Knollmann BC, Miller T, Bell M, Zhao J, Sirenko SG, Diaz Z, Guzman G, Xu Y, Wang Y, Kerrick WG, Potter JD. F110I and R278C troponin T mutations that cause familial hypertrophic cardiomyopathy affect muscle contraction in transgenic mice and reconstituted human cardiac fibers. J Biol Chem. 2005;280:37183-37194.

34. Jenkins SJ, Hutson DR, Kubalak SW. Analysis of the proepicardium-epicardium transition during the malformation of the RXRalpha-/- epicardium. Dev Dyn. 2005;233:1091-1101.

35. Apte SS. A disintegrin-like and metalloprotease (reprolysin type) with thrombospondin type 1 motifs: the ADAMTS family. Int J Biochem Cell Biol. 2004;36:981-985.

36. Sengbusch JK, He W, Pinco KA, Yang JT. Dual functions of [alpha]4[beta]1 integrin in epicardial development: initial migration and long-term attachment. J Cell Biol. 2002;157:873-882.

37. Gross JC, Schreiner A, Engels K, Starzinski-Powitz A. E-cadherin surface levels in epithelial growth factor-stimulated cells depend on adherens junction protein shrew-1. Mol Biol Cell. 2009;20:3598-3607.

38. Petrou P, Pavlakis E, Dalezios Y, Chalepakis G. Basement membrane localization of Frem3 is independent of the Fras1/Frem1/Frem2 protein complex within the sublamina densa. Matrix Biol. 2007;26:652-658.

39. Sekine K, Kawauchi T, Kubo K, Honda T, Herz J, Hattori M, Kinashi T, Nakajima K. Reelin controls neuronal positioning by promoting cellmatrix adhesion via inside-out activation of integrin $\alpha 5 \beta 1$. Neuron. 2012;76:353-369.

40. Liu J, Stainier DY. Tbx5 and Bmp signaling are essential for proepicardium specification in zebrafish. Circ Res. 2010;106:1818-1828.

41. Xie L, Hoffmann AD, Burnicka-Turek O, Friedland-Little JM, Zhang K, Moskowitz IP. Tbx5-hedgehog molecular networks are essential in the second heart field for atrial septation. Dev Cell. 2012;23:280-291.

42. Singh MK, Lu MM, Massera D, Epstein JA. MicroRNA-processing enzyme Dicer is required in epicardium for coronary vasculature development. J Biol Chem. 2011;286:41036-41045. 
43. Phillips HM, Hildreth V, Peat JD, Murdoch JN, Kobayashi K, Chaudhry B, Henderson DJ. Non-cell-autonomous roles for the planar cell polarity gene Vang12 in development of the coronary circulation. Circ Res. 2008;102:615-623.

44. Rhee DY, Zhao XQ, Francis RJ, Huang GY, Mably JD, Lo CW. Connexin 43 regulates epicardial cell polarity and migration in coronary vascular development. Development. 2009;136:3185-3193.

45. Mikawa T, Gourdie RG. Pericardial mesoderm generates a population of coronary smooth muscle cells migrating into the heart along with ingrowth of the epicardial organ. Dev Biol. 1996;174:221-232.
46. Nadeau M, Georges RO, Laforest B, Yamak A, Lefebvre C, Beauregard J, Paradis P, Bruneau BG, Andelfinger G, Nemer M. An endocardial pathway involving Tbx5, Gata4, and Nos3 required for atrial septum formation. Proc Natl Acad Sci U S A. 2010;107:19356-19361.

47. Zhu Y, Gramolini AO, Walsh MA, Zhou YQ, Slorach C, Friedberg MK, Takeuchi JK, Sun H, Henkelman RM, Backx PH, Redington AN, Maclennan DH, Bruneau BG. Tbx5-dependent pathway regulating diastolic function in congenital heart disease. Proc Natl Acad Sci U S A. 2008;105:5519-5524.

\section{Novelty and Significance}

\section{What Is Known?}

- The proepicardial organ/proepicardium is a grape-like structure located caudal to the heart that contributes precursor cells during cardiovascular development to form the epicardium, pericardium, coronary vessels, and cardiac fibroblasts through a series of coordinated events involving regulation of gene expression and cell behavior.

- During cardiovascular development, Tbx5 mRNA is detected in the embryonic chick proepicardial organ, and TBX5 protein is expressed in the epicardium and coronary vessels of the fetal human heart.

- TBX5 overexpression in the proepicardial organ disrupts proepicardial cell migration to the coronary vasculature in the embryonic chick heart, whereas loss of Tbx5 in the developing zebrafish heart leads to the absence of proepicardium formation.

\section{What New Information Does This Article Contribute?}

- We developed strategies to investigate Tbx5 activity in formation and maturation of the epicardium and coronary vessels through retroviralmediated transgenesis in the embryonic chick and tissue-specific deletion of $T b \times 5$ in the developing mouse proepicardium.

- Our findings reveal that proepicardium -specific loss of mouse Tbx5 causes delayed epicardial attachment to the myocardium and subepicardial accumulation of epicardial-derived cells that, we believe, precipitates a cascade of events to impair epicardial maturation and formation of the coronary vasculature, inhibit cardiac growth, and elicit myocardial hypoxia in the mammalian heart.

- Tbx5 is indispensable for normal epicardial formation and coronary vasculogenesis during embryogenesis and this may be reflected by the pericardial agenesis and anomalous coronary arteries seen in some human patients with Holt-Oram syndrome and TBX5 mutations.

Previous studies identified Tbx5 roles in myocardial, endocardial, and cardiac conduction system development. However, potential Tbx5 activity in the epicardium and mammalian coronary vasculogenesis remains unidentified. We show that Tbx5 expression in the proepicardium and epicardium is heterogeneous. Our augmentation of Tbx5 expression in embryonic chick proepicardial organ and epicardium reveals its requirement in proepicardial cell migration for formation and maturation of the epicardium and incorporation of epicardial-derived cells into coronary blood vessels. Mice genetically engineered for proepicardial-specific Tbx5 loss ( $T b \times 5^{\text {epi- }}$ ) are born at sub-Mendelian ratios. Although the proepicardium forms properly in these mice and proepicardial cells begin migration toward the myocardium at embryonic day (E) 10.5 , Tbx5 deficiency delays epicardial cell attachment to the E11.5 myocardium. Cell adhesion and extracellular matrix gene expression are reduced in E11.5 Tbx $5^{\text {epi- }-~}$ hearts. Although epicardial cells attach to myocardium by E12.5, $T b \times 5^{\text {epi- }}$ embryos exhibit other defects, including impaired epicardial-derived cell production and invasion into the myocardium, compromised establishment of coronary vessels, decreased myocardial growth and myocardial hypoxia. Adult $T b \times 5^{\text {epi- }}$ mice are intolerant to exercise. We conclude that Tbx5 is required in normal epicardial formation and coronary vasculogenesis. This requirement provides insight into pericardial agenesis and anomalous coronary arteries observed in patients with HOS and TBX5 mutations. 